\section{UNCLASSIFIED}

RECORDS ADMINISTRATION

HII

Ro138671
DP - 115

Engineering

\title{
A SIMPLIFIED SAFETY ROD ACTUATOR
}

by

D. Baker, Jr., W. E. Llewellyn, J. P. Maloney

Pile Engineering Division

May 1955

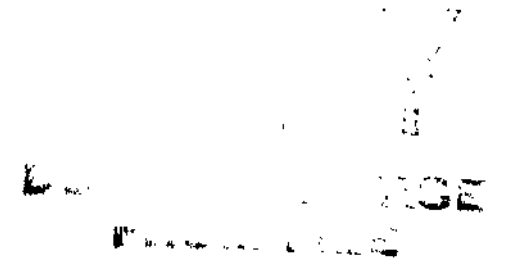

E. I. du Pont de Nemours \& Co.

Explosives Department - Atomic Energy Division

Technical Division - Savannah River Laboratory 


\section{A SIMPLIFIED SAFETY ROD ACTUATOR}

by

D. Baker, Jr., W. E. Llewellyn, J. P. Maloney

Pile Engineering Division

$$
\text { Work done by }
$$

T. J. Atterbury,

D. Baker, Jr., J.W. Croach,

W. N. Harris, H. J. Hollberg,

W. E. Llewellyn, J. P. Maloney,

G. W. Richardson, V. W. Walker

May 1955

E. I. du Pont de Nemours \& Co.

Explosives Department - Atomic Energy Division

Technical Division - Savannah River Laboratory

Printed for

The United States Atomic Energy Commission Contract $\operatorname{AT}(07-2)-1$ 


\section{ABSTRACT}

A winch assembly that operates a safety rod for a nuclear reactor was developed to decelerate the rod after it drops under emergency conditions into the reactor. The assembly is designed to convert the kinetic energy of the falling rod as it nears its limit of travel to rotational energy in the winch. The conversion is accomplished without the aid of an external power source or an auxiliary snubbing mechanism.

External Distribution according to TID-4500, 9th Edition 


\section{INTERNAL DISTRIBUTION}

No. of

Copies

(5) AEC, SROO

(I) M. H. WahI -

C. W. J. Wende

(1) W。E. Llewellyn

(15) TiS File

(I) TIS File Record Copy
Augusta, Ga.

Savannah River Laboratory 

This category covers engineering studies, materials testing, and equipment design and
operation of interest to the AEC program.

No. of Copies

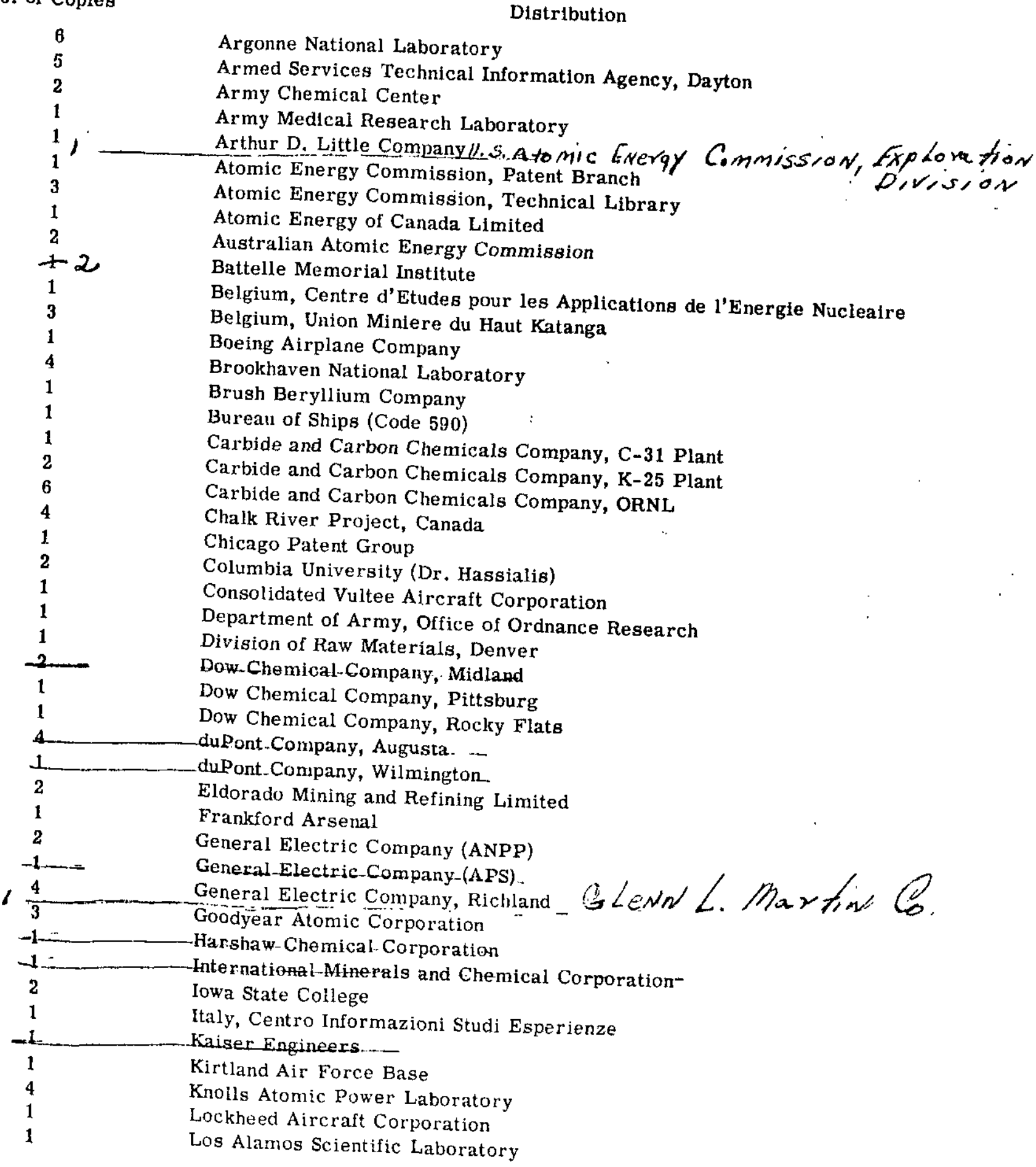




\section{ENGINEERING (Cont'd.)}

No. of Copies

\section{Distribution}

Mallinckrodt Chemical Works

Massachusetts Institute of Technology (Dr. Hardy)

Mound Laboratory

National Advisory Committee for Aeronautics, Cleveland

National Bureau of Standards, Atomic Energy Project

National Bureau of Standards (Library)

National Lead Company, Inc., Winchester

National Lead Company of Ohio

National Research Corporation

National Research Council, Canada

Naval Medical Research Institute

Naval Research Laboratory

New Brunswick Laboratory

Newpont News Shipbuilding and-Dry Dock Gompany .....

New York Operations Office

North American Aviation, Inc.

Nuclear Development Associates, Inc.

Nuclear Metals, Inc. (Dr. Kaufmann)

Oak Ridge Institute of Nuclear Studies

Phillips Petroleum Company

Princeton University

Public Health Service

RAND Corporation

Sandia Coxporation

Sylvania Electric Products, Inc.

Technical Information Service, Oak Ridge

Tokyo University

United Aircraft Corporation

United Kingdom Scientific Mission

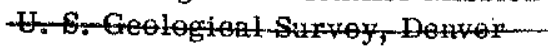

U. S. Geological Survey (RCS-TEPCO), Denver

U. S. Geological Survey, Washington

U. S. Naval Radiological Defense Laboratory

UCLA Medical Research Laboratory

University of California Radiation Laboratory, Berkeley

University of California Radiation Laboratory, Livermore

University of Michigan (Dr. Gomberg)

University of Rochester, Atomic Inergy froject

Vitro Corporation of America

Walter Kidde Nuclear Laboratories, Inc.

Watertown Arsenal

Weil, Dr. George L.

Westinghouse Electric Corporation

$300-$

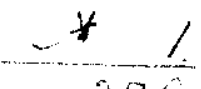

sygat lorps

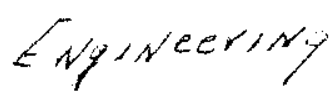

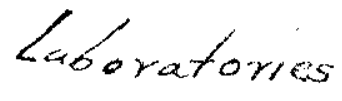




\section{TABLE OF CONTENTS}

INTRODUCTION

SUMMARY

4

DISCUSSION

Conical Drum Concept

Design Considerations Idealized Analysis

Approximate Analysis

The Design of a Prototype Model

APPENDIX A - SPECIAL FEATURES OF PROTOTYPE ACTUATOR

APPENDIX B - ARRANGEMENT FOR GANGED SAFETY RODS

\section{LIST OF FIGURES}

Figure 1 Cross Section of Prototype Model of the Conical Drum Actuator

Figure 2 Prototype Model of the Conical Drum Actuator With Side Plate Removed

Figure 3 Prototype Model of the Conical Drum Actuator

Figure 4 Insertion of Safety Rod - Curve of Distance vs. Time

Figure 5 Power Circuits in Conical Drum Actuator

Figure 6 Detail of the Eccentric in the Shaft

Figure 7 Schematic Arrangement, Unwinding Cable

Figure 8 Lowering Mechanism

Figure 9 Conical Drum Actuator for Ganged Safety Rods 


\section{A SIMPLIFIED SAFETY ROD ACTUATOR}

\section{INTRODUCTION}

Safety rod actuators for nuclear reactors frequently utilize gravitational force for emergency insertion of the safety rods. In such designs the rods must be decelerated before reaching the end of their travel to prevent damage to the reactor and to the auxiliary components.

Where the safety rods are supported vertically by cables, the snubbing force is applied at the top of the cable to avold backlash. The cable is wound on a drum that is coupled with an electric clutch to a gearmotor. The clutch is released to permit the rods to fall and is electrically re-engaged near the bottom of the rod's travel to decelerate the rod.

Ideally, an actuator should not depend on an external source of power to activate the snubbing mechanism, since fallure of the power can result in serious damage.

This report describes an improved design for a safety rod actuator which has a snubbing device that requires no external power source for its activation.

\section{SUMMARY}

The actuator developed at the Savannah River Laboratory for decelerating a safety rod employs a winch drum assembly that is designed to dissipate the energy of the falling rod during its last few feet of travel by rapidly accelerating the drum. The snubbing is accomplished by permitting the last few turns of the cable to unwind from a spiral groove that is cut in a conical surface on one end of the drum. As the cable unwinds from the spiral groove and approaches the apex of the cone, the downward velocity of the rod approaches zero and the drum is accelerated to a high angular velocity. The cable is anchored to a shaft that serves as the axle of the conical drum. The drum can rotate freely relative to the shaft, thereby permitting the rod to remain in its down position after an emergency drop without the cable being rewound by the rapidly rotating drum. 
One of the simplest and most reliable methods for quick insertion of a safety rod 1 s to allow the rod to fall freely. Reactor damage, cable backlash, and buckling of the rod must be prevented by decelerating these components with a snubbing force applied at the actuator. The snubbing device described in this report is a cable windlass designed in such a way that the energy of the falling rod is dissipated by accelerating the drum during the last few feet of rod trave1. The snubbing is accomplished by providing a conical surface on one end of the drum that supports the cable. The last few turns of the cable groove form a spiral on the conical surface and terminate at the apex of the cone.

When the rod is in the up position, its cable is fully wound on the drum. When the rod drops, the drum is accelerated at a constant rate by the unwinding cable until the cable leaves the cylindrical surface of the drum and begins to unwind from the spiral groove. At this point the angular acceleration of the drum begins to increase rapidly and the velocity of the falling rod decreases.

The cable fits in a groove that is continuous from the drum to the shaft that serves as the axle of the drum. The terminating point of the groove is at the center of rotation of the shaft. As the unwinding cable approaches this point, the downward velocity of the cable and rod approaches zero, but the angular velocity of the conical drum reaches a maximum. Since the drum can rotate freely relative to the shaft, the cable merely hangs from the shaft while the drum rotates and expends its energy in overcoming bearing friction.

DESIGN CONSIDERATIONS

In the design of a conical drum actuator for a particular application, the weight of the safety rod and the distance through which the rod operates are generally specified. In most cases there are specifications that require the rod to be partially inserted a given distance and/or fully inserted within a given time. In addition, there are often special requirements that limit the size and weight of the actuator. The designer must choose the parameters of the actuator so that the desired performance will be obtained. The parameters that must be chosen are (1) radius of the drum, (2) effective inertia of the drum, (3) snubbing distance, and (4) shape of the spiral on the conical portion of the drum. Finally, the maximum tension that is developed in the cable as the rod is snubbed should not exceed a safe value, nor should the snubbing action cause excessive "bounce" that might result in backlash of the cable.

For a particular actuator, the exact calculation of the position of the rod and the tension in the cable as a function of time would require taking into account frictional effects and the elastic properties of the cable. Such a calculation would be more complicated than is normally required for practical purposes. The calculation is much simplified if friction and cable stretch are neglected. The necessary equations are developed in the following section on "Idealized Analysis". 
Subsequently, an "Approximate Analysis" is given that will suffice for practical purposes of design.

\section{Idealized Analysis}

At any instant the kinetic energy of the rod, $E_{R}$, plus the kinetic energy of the drum, $E_{D}$, equals the weight of the rod, $W$, times the distance it has dropped, $S: *$

$$
\mathrm{E}_{\mathrm{R}}+\mathrm{E}_{\mathrm{D}}=W S
$$

Dividing by $E_{R}$ and rearranging, one obtains:

$$
E_{R}=\frac{W S}{1+E_{D} / E_{R}}
$$

Since $E_{D}$ equals $\frac{1}{2} I \omega^{2}$ where $\omega$ is the angular velocity of the drum; and $\mathrm{E}_{\mathrm{R}}$ equals $\frac{1}{2} \mathrm{Wv}^{2}$ where $\mathrm{v}$ is the linear velocity of the rod, then:

$$
E_{R}=\frac{W S}{I+\frac{I \omega^{2}}{W v^{2}}}
$$

Since the Iinear velocity, $v$, of the rod and cable equals the angular velocity, $\omega$, times the torque radius, $r$, of the cable as it unwinds from the drum, then:

$$
E_{R}=\frac{W S}{1+\frac{I}{W r^{2}}}
$$

The net force, $F$, acting on the rod times an incremental distance, dS, that the rod has dropped equals the kinetic energy in the rod, therefore:

$$
F=\frac{d}{d S}\left(E_{R}\right) \text { or } \quad F=\frac{d}{d S}\left(\frac{W S}{1+\frac{I}{W r^{2}}}\right)
$$

The net force on the rod at any time is the difference between the force of gravity and the cable tension, $T$, so:

$$
F=W-T \text { or } T=W-\frac{d}{d S}\left(\frac{W S}{1+\frac{I}{W r^{2}}}\right)
$$

The path of the spiral determines $r$ as a function of $S$. For a given spiral, the tension in the cable and the net force on the rod can be computed from equations (3) and (2) as a function of $S$. In particular, the maximum tension can be found.

* Symbols are listed in Appendix C. 
Since the acceleration is given by $a=\frac{F g}{W}$, the relationship between acceleration and distance $S$ is also known. The instantaneous velocity of the rod is then determined as follows:

$$
a=\frac{d v}{d t}=v \frac{d v}{d S} \quad \text { or } \quad v^{2}=a \int_{0}^{S} \operatorname{ads}
$$

from:

The time of travel to any given position can then be computed

$$
t=\int_{0}^{S} \frac{d S}{v}
$$

\section{Approximate Analysis}

Before snubbing begins, the cable unwinds from the portion of the drum that has a constant diameter and the rod falls with a constant acceleration:

$$
a=\frac{g}{1+\frac{I}{W r_{0}^{2}}}
$$

The time for the rod to fall to the position $\left(S_{1}\right)$ where snubbing begins is:

$$
t_{1}=\sqrt{\frac{2 S_{1}}{a_{1}}}=\sqrt{\frac{2 S_{1}\left(I+W r_{0}^{2}\right)}{g W r_{0}^{2}}}
$$

The additional time for the rod to reach the end of its travel, after snubbing has begun, is eenerally small compared to $t_{l}$. A satisfactory approximation of this time interval is given by the assumption that the rod is brought to rest with constant deceleration in the interval. The velocity of the rod at the beginning of the interval is:

$$
v_{1}=a t_{1}=\frac{g t_{1}}{1+\frac{I}{W r_{0}^{2}}}
$$

will be:

For uniform deceleration over the distance $S_{2}-S_{1}$ the time

$$
t_{2}-t_{1}=\frac{2\left(S_{2}-S_{1}\right)}{v_{1}}=\frac{2\left(S_{2}-S_{1}\right)\left(1+\frac{I}{W r_{0}}\right)}{g t_{1}}
$$

The total time of insertion can therefore be approximated by: 


$$
t_{2}=\sqrt{\frac{2 S_{1}\left(I+W r_{0}^{2}\right)}{g W r_{0}^{2}}}+2\left(S_{2}-S_{1}\right) \sqrt{\frac{I+W r_{0}^{2}}{2 S_{1} g W r_{0}^{2}}}
$$

Sufficient information about the tension in the cable can be obtained by a consideration of appropriate average tensions. Ordinarily, the maximum tension will occur as the rod approaches the position of full insertion. The reason for this is that there is a maximum curvature that can be practically used with a given cable. When the cable has unwound from the spiral to the point of maximum curvature, there is little control that can be exercised over the remaining distance of travel.

If the position of the rod is $S_{m}$ and the torque radius is $r_{m}$ when the cable has unwound to the point of maximum curvature, the kinetic and potential energy of the rod are:

$$
\begin{aligned}
& \text { Kinet1c Energy }=\frac{W S_{m}}{1+\frac{I}{W r_{m}^{2}}} \\
& \text { Potential Energy }=W\left(S_{2}-S_{m}\right)
\end{aligned}
$$

The total energy of the rod must be expended by doing work on the cable in the remaining distance of travel. The average tension in the cable over the distance $S_{m}$ to $S_{2}$ is:

$$
T_{\text {avg }} \text { (terminating) }=W+\frac{W_{m}}{\left(S_{2}-S_{m}\right)\left(1+\frac{I}{W r_{m}{ }^{2}}\right)}
$$

It is possible to control the termination of the cable in such a way that the tension is theoretically constant over the interval from $S_{m}$ to $S_{2}$, but the effect of cable stretch is generally so great that such pains are unwarranted. The average tension given by equation (5) should be made substantialiy less than the ultimate strength of the cable.

The average tension in the cable for the distance the rod moves during snubbing is given by:

$$
\mathrm{T}_{\text {avg }}(\text { snubbing })=W+\frac{W S_{1}}{\left(S_{2}-S_{1}\right)\left(1+\frac{1}{W r_{0}{ }^{2}}\right)}
$$


The maximum tension in the cable will exceed the larger of the two average tensions given by equations (5) and (6) by a factor of two or three.

THE DESIGN OF A PROTOTYPE MODEL

The prototype model is shown in section view in Figure 1 . The conical drum $(F)$ is attached to a hub (E) that is seated on bearings. The bearings are mounted on the shaft $(H)$ in which the cable is anchored, and the shaft in turn is seated in bearings tnat are pressed into a supporting frame $(\mathrm{J})$. The cable and rod are moved normally by driving the drum in either direction by a geamotor connected through an electric clutch (B). The purpose of the clutch is to release the drum from the gearmotor, and allow the rod to drop freely when an emergency drop is required or when the power supply falls.

When the cable and rod are to be moved upward, the shaft must turn and wind up the cable until it pays onto the drum. The torque is transmitted from the drum to the shaft by a key $(K)$, which engages the drum in the up direction only. The drum can rotate freely in the opposite direction on the shaft after an emergency drop.

The moment of inertia necessary to absorb the energy is provided by a flywheel (N) connected to the drum and hub through a 3 to 1 gear ratio. Since the effective moment of inertia of the flywheel varies as the square of the gear ratio, the gearing permits the use of a flywheel having only $1 / 9$ the moment of inertia of one connected directly to the drum, and allows a reduction in the welght of the actuator. A curve of the height vs. time of fall is shown in Figure 4.

The remaining details of the actuator shown in Figure 1, such as the lowering mechanism within the hub and the eccentric in the shaft, are described in Appendix A. The power circuits are shown in Figure 5.

A description of an actuator for operating gangs of safety rods is given in Appendix $B$.
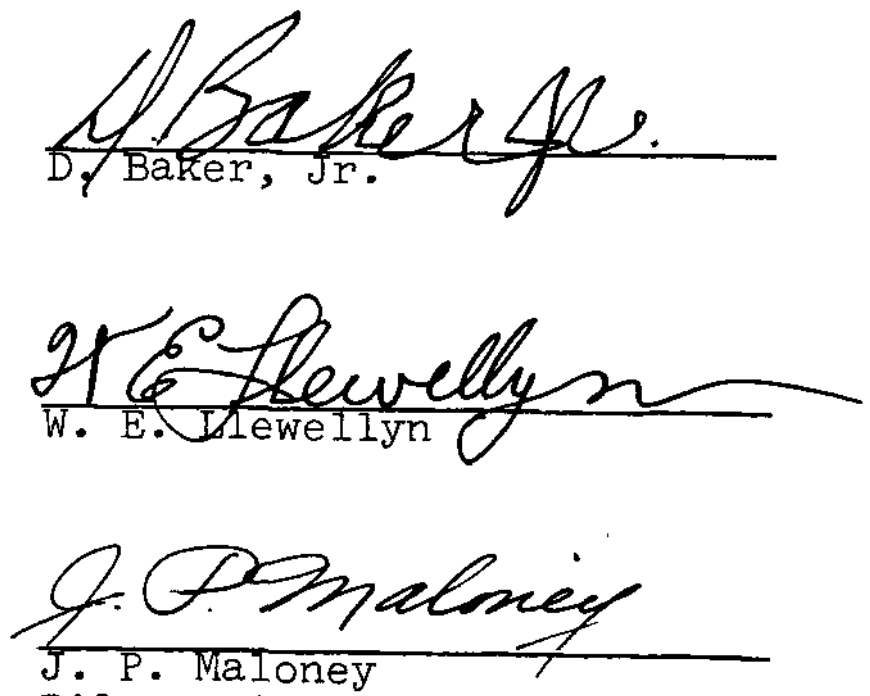

Pile Engineering Division

Mechanical Development Group 


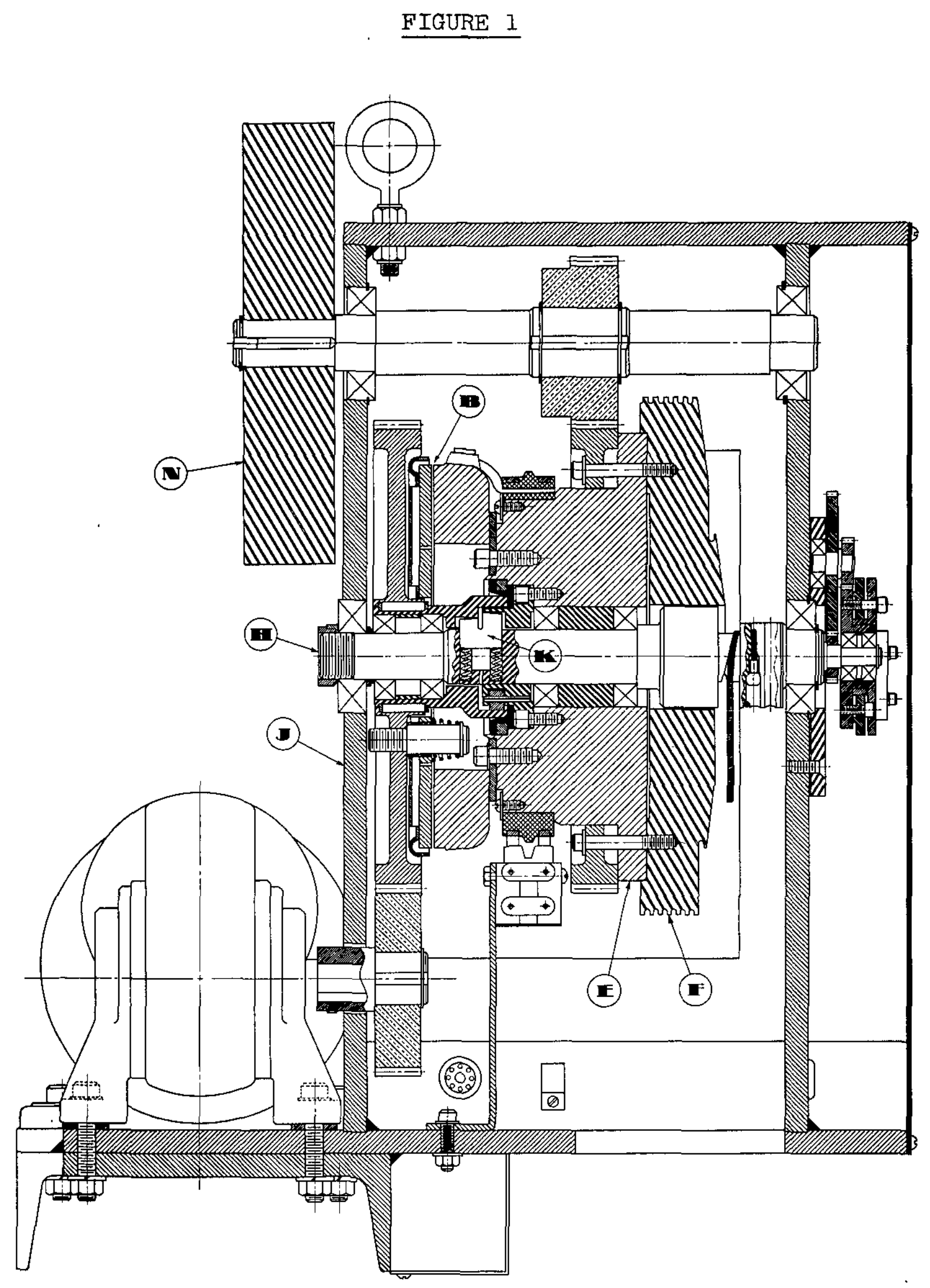

CROSS SECTION OF PROTOTYPE MODEL OF THE CONICAL DRUM ACTUATOR 
EIGURE 2

PROTOTYPE MODEL OF CONICAL DRUM ACTUATOR WITH SIDE PLATE REMOVED

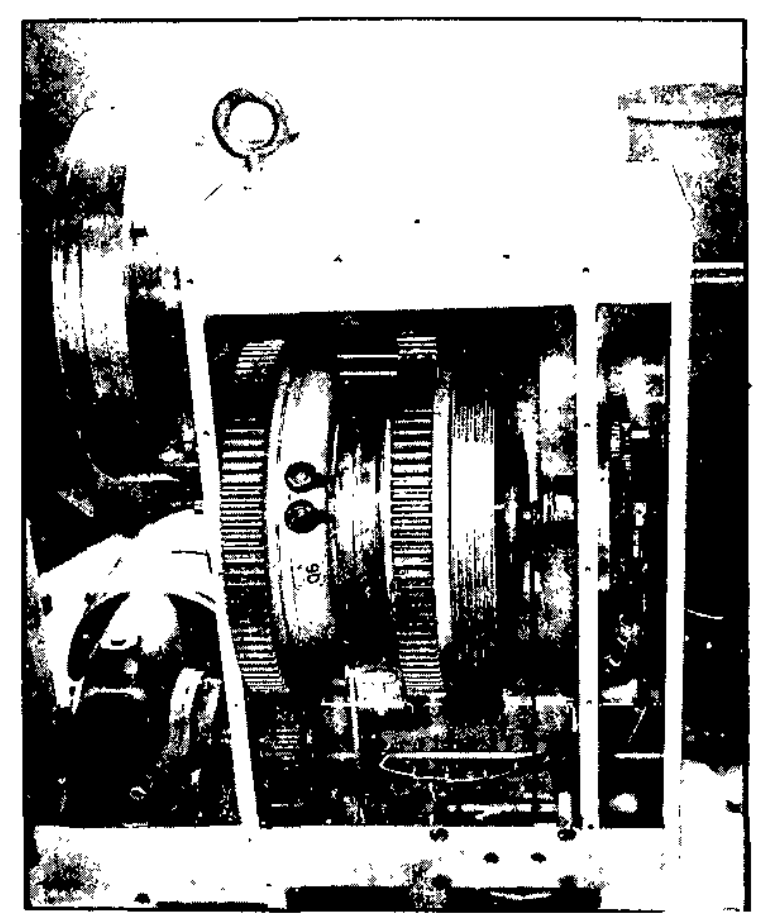

\section{FIGURE 3}

PROTOTYPE MODEL OF CONICAL DRUM ACTUATOR

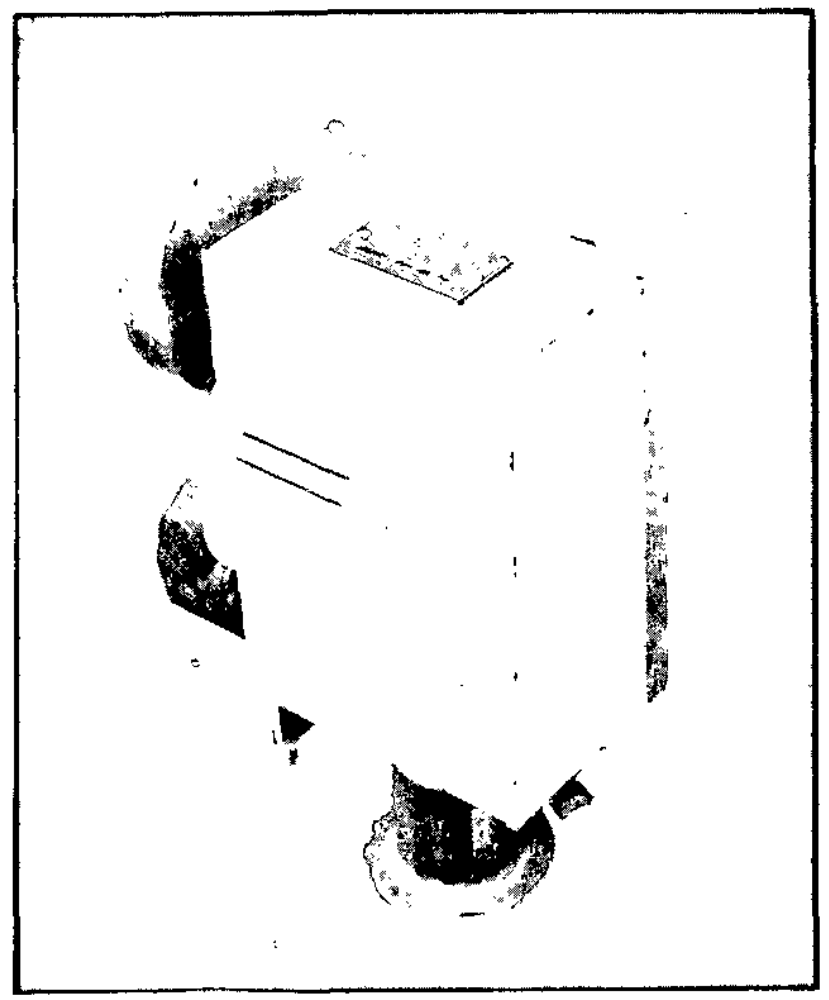




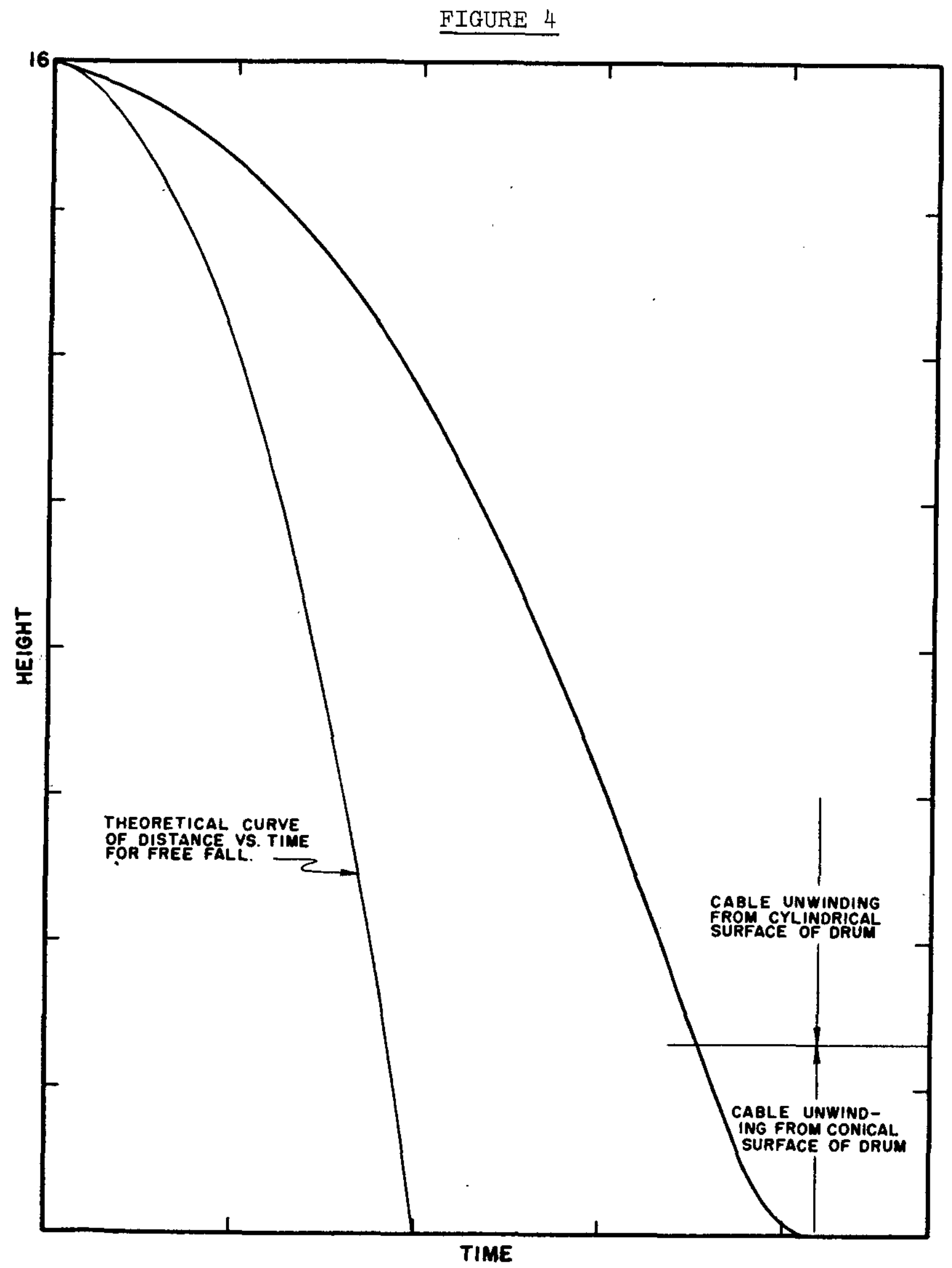

INSERTION OF SAFETY ROD - CURVE OF DISTANCE VS. TIME CONICAL DRUM SAFETY ROD ACTUATOR PROTOTYPE MODEL, FIGURE 1 


\section{FIGURE 5}

(
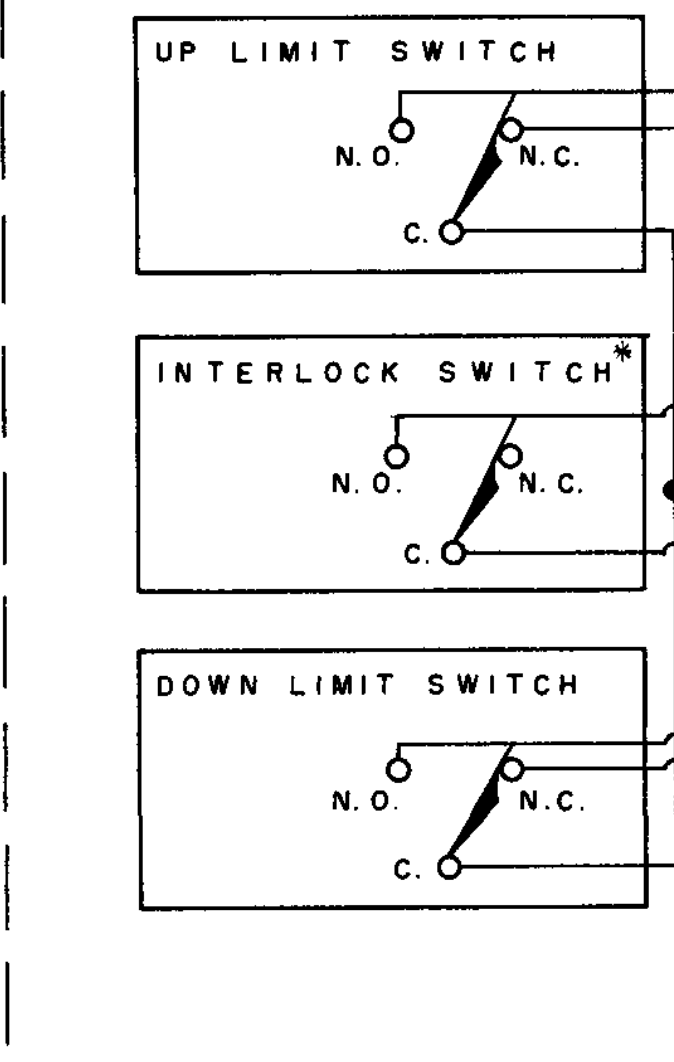

ACTUATOR

1
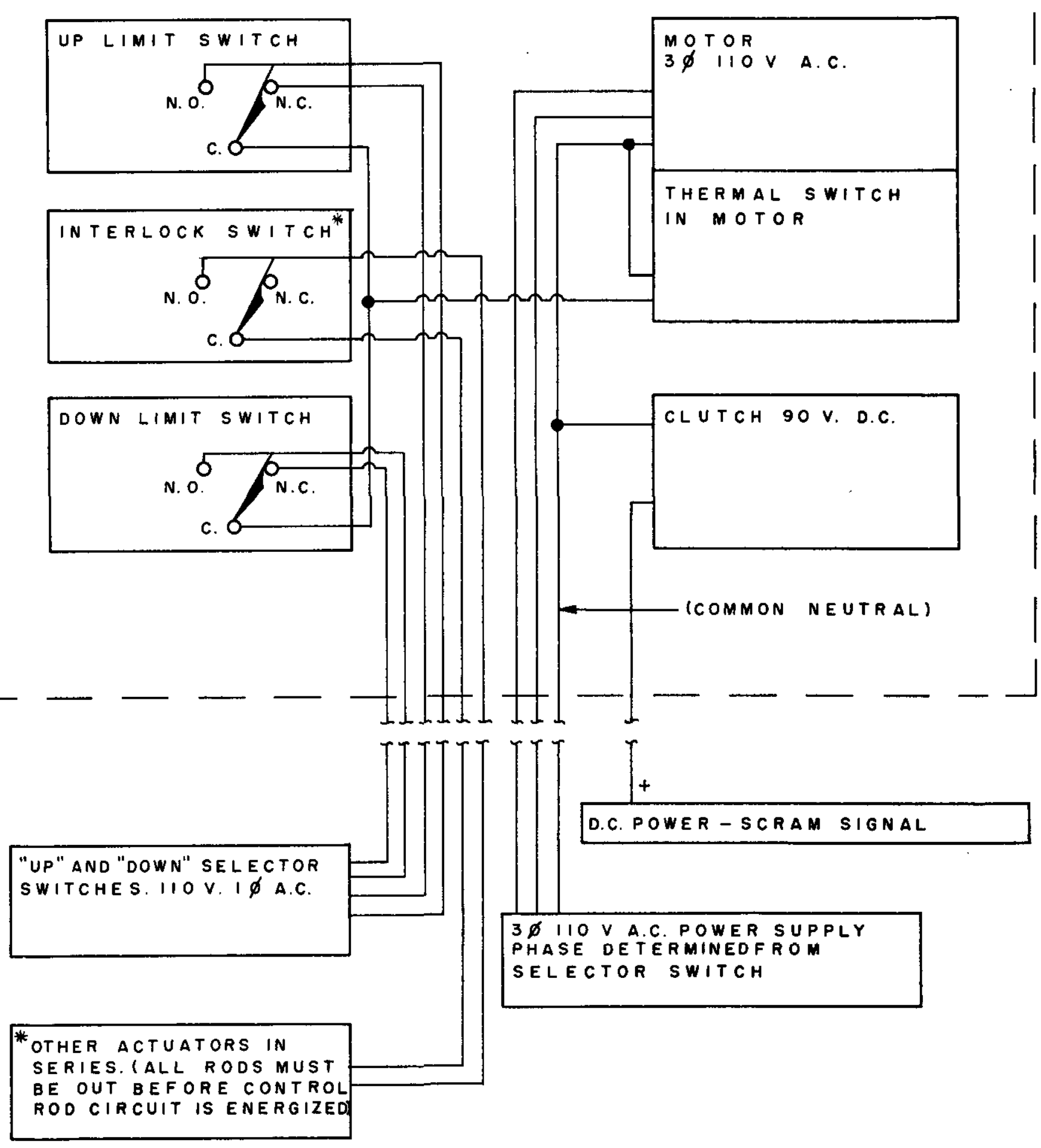

POWER CIRCUITS IN CONICAL DRUM ACTUATOR 
FIGURE 6
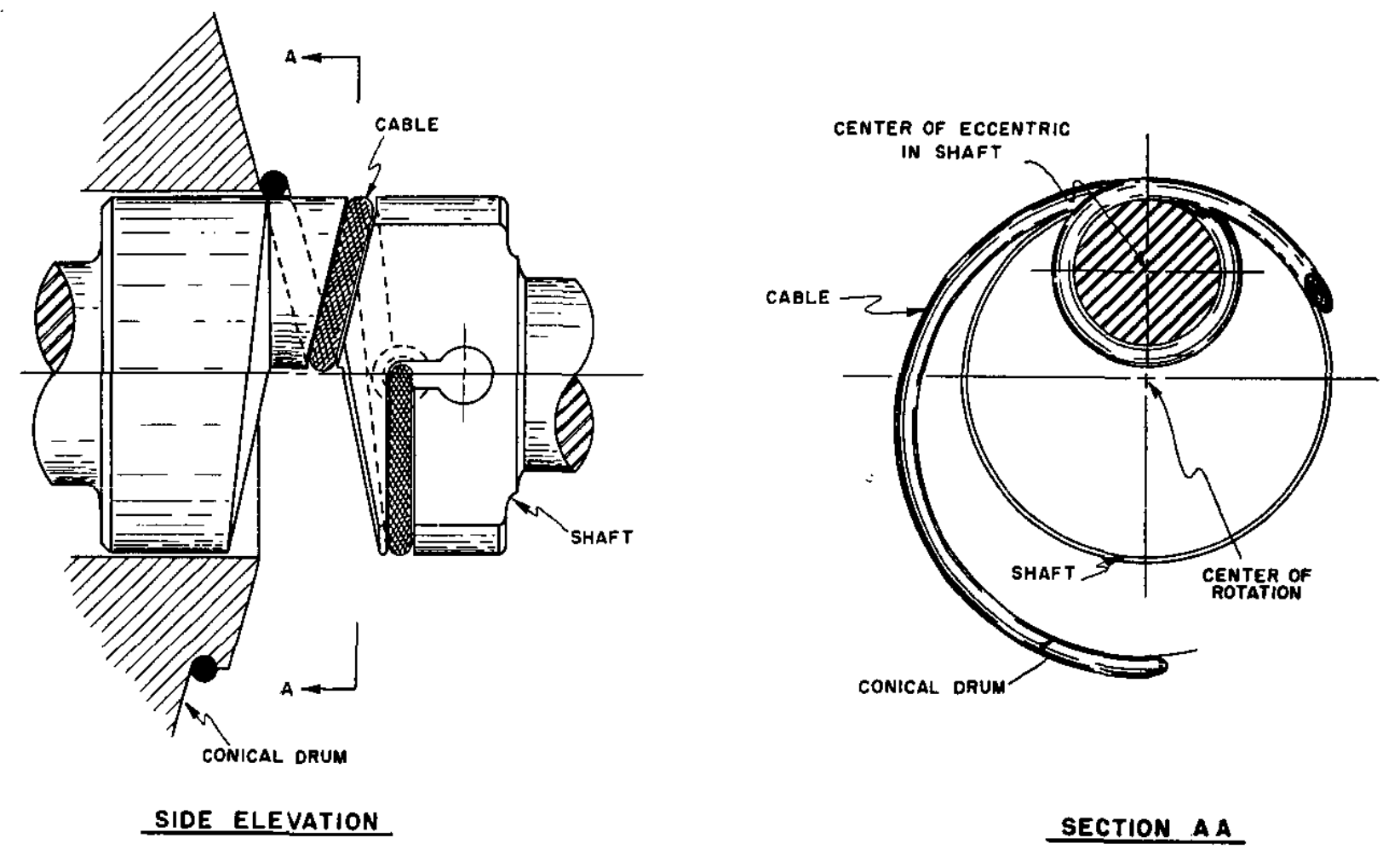

SECTION AA

DETAIL OF THE ECCENTRIC IN THE SHAFT, CONICAL DRUM ACTUATOR 


\section{FIGURE 7}
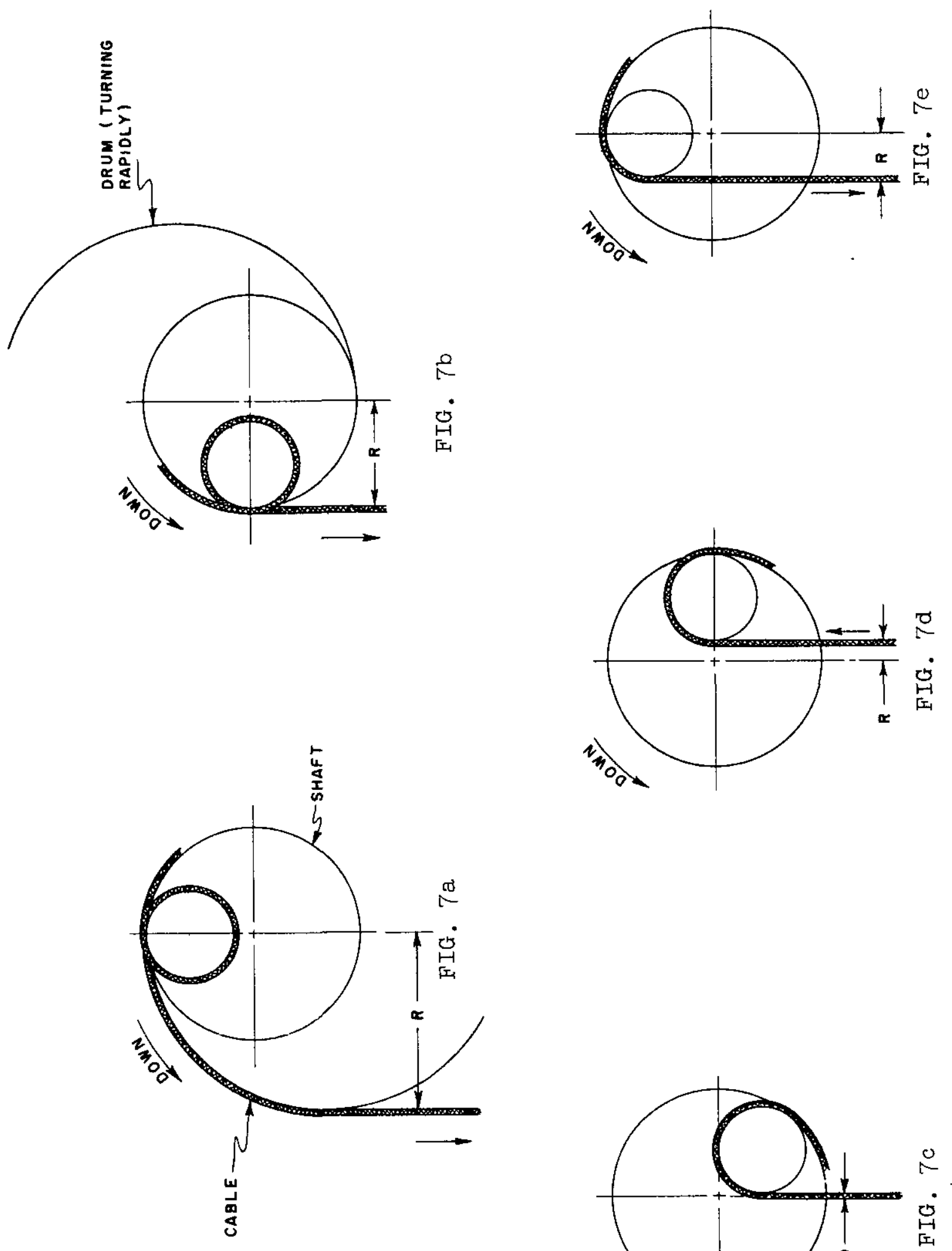

暗

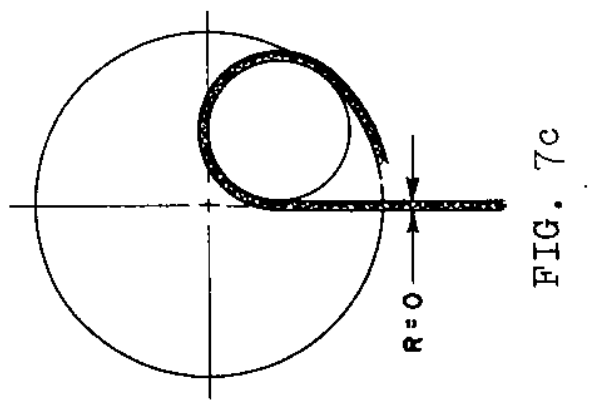




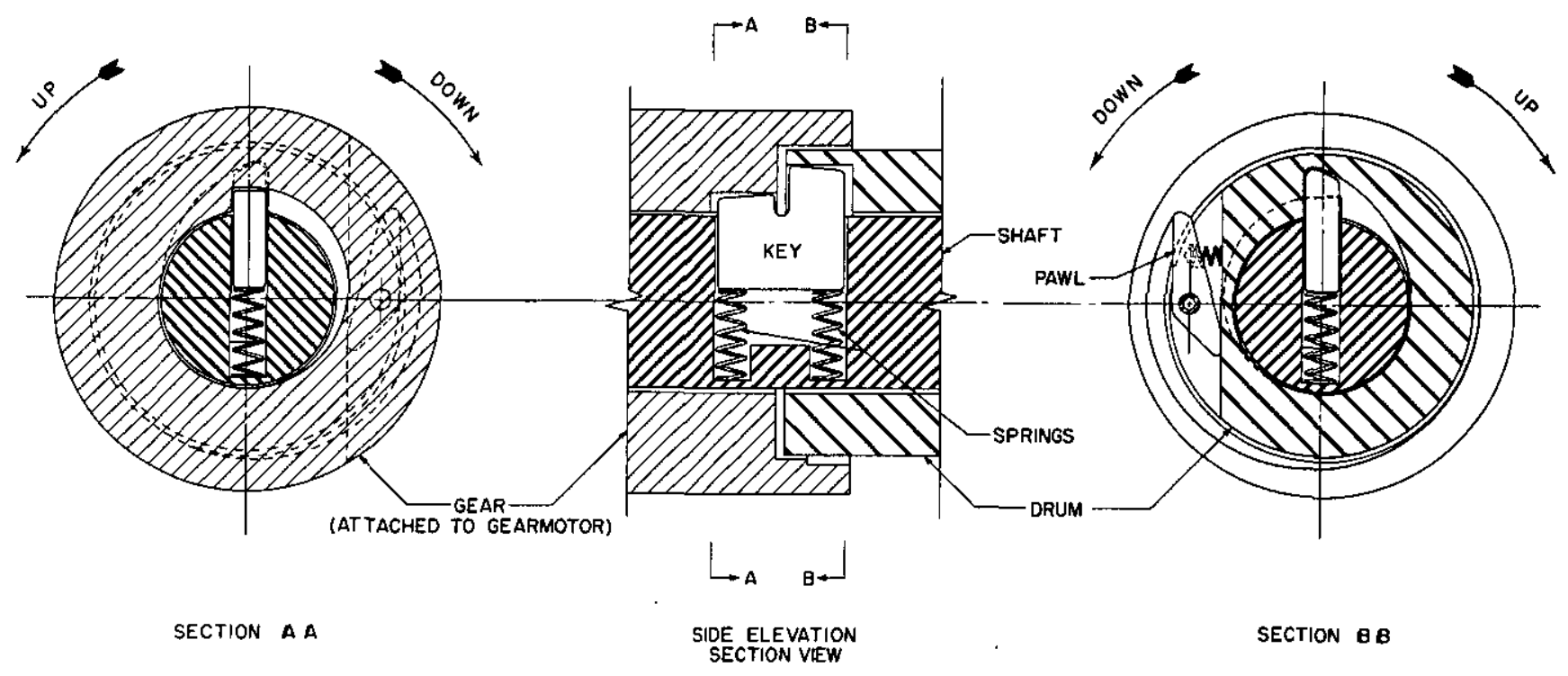

LOWERING MECHANISM 


\section{FIGURE 9}

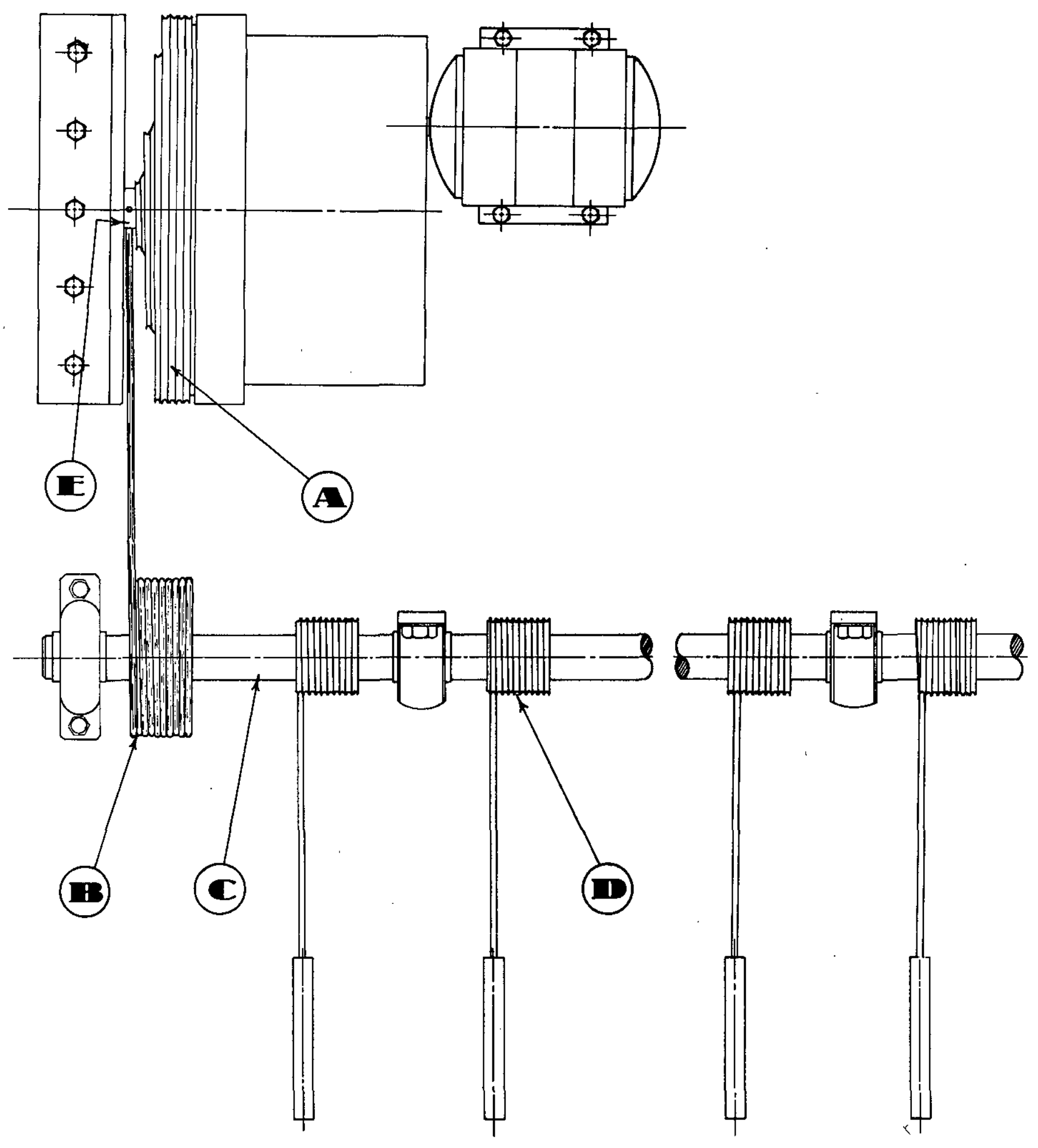

CONICAL DRUM ACTUATOR FOR GANGED SAFETY RODS 
Latches are frequently employed to connect the cables to the safety rods. A latch is usually designed in such a way that it cannot be de-latched when 1 it is supporting the weight of the safety rod. This feature prevents damage being done to the pile by an accidentally dropped rod. One method of remote de-latching of the rod requires that the actuator be capable of seating the safety rod in the pile so the supporting cable is slack. The actuator must be able to lower the rod a short distance beyond the fully snubbed position after a scram.

The lowering action is accomplished by an eccentric, similar to a connecting rod journal on a crankshaft, In the shaft that serves as the axle for the conical drum. The cable which unwinds from the spiral groove in the confcal drum is wound around the eccentric in the shaft as shown in Figure 6.

During an emergency drop, the cable unwinds from the spiral groove and then from the eccentric in the shaft as shown in Figure $7 a$ through $7 \mathrm{e}$.

Figure $7 \mathrm{a}$ shows the drum and shaft moving together as the cable unwinds. Figure $7 \mathrm{~b}$ shows the relative positions of the components as the cable begins unwinding from the shaft. At this time the downward velocity of the cable is low and the angular velocity of the drum is high due to the short unwinding radius, $R$. When $R$ reaches zero, as shown in Figure $7 \mathrm{c}$, the cable merely hangs from the shaft while the drum continues to rotate until stopped by bearing friction. Also, for this relative position between cable and shaft, the safety rod is a few inches from being fully seated in the reactor. To lower the cable (and safety rod) an additional amount, the shaft must be turned by the gearmotor, because the cable must be lifted slightly to pass through the position shown in Figure 7d. Having passed this position and having reached the position shown in Figure $7 \mathrm{e}$, the cable, due to the weight of the hanging rod, can rotate the shaft. The slight impact that would occur during this final lowering is avolded by making the drum and flywheel rotate with the shaft and by terminating the cable at the center of rotation of the shaft.

The drum is made to rotate with the shaft by designing two pickup points on the key which is used to engage the drum to the shaft for upward movement of the cable. As shown in Figure 8 , the higher of the two points permits drum-to-shaft engagement for up direction of rotation only, and the lower point permits gearmotor-to-shaft engagement for down direction of rotation only. Also, the gearmotor or gear cannot pick up the shaft until the gear has engaged itself to the drum with the pawl and turned the drum to the point where it is perfectly aligned with the shaft. In this way the shaft $w 111$ not rotate rapidly and independently from the drum during the final lowering cycle, but will be required to move slowly due to the high inertia of the drum. When the gear is connected to the drum through the electric clutch for up direction of rotation, the drum will pick up the shaft regardless of the relative position of the gear and shaft because of the difference in height of the pickup points on the key. 
The lowering mechanism described above requires no additional

power signals from the control room. The mechanism operates automatically with the normal "up", "down"e and "scram" electrical signals.

\section{APPENDIX B}

ARRANGEMENT FOR GANGED SAFETY RODS

If the geometry of a particular reactor and the available space permit operation of a number of safety rods from one prime mover, the conical drum concept offers an attractive method for snubbing the rods. In addition to the advantages gained by the absence of an external power source for snubbing, the system can be designed with very few moving parts and little auxiliary equipment. A schematic arrangement of a ganged system is shown in Figure 9.

The effect of the conical drum snubbing could be compounded by replacing the cylindrical drum " $B$ " with a conical drum, so arranged that as the unwinding cable approached the apex of the conical drum "A", the winding cable would approach the base of conical drum "B". This in turn would result in relatively lightweight drums with only the cable connecting the drums being of substantial strength. 


\section{APPENDIX C}

NOMENCLATURE - SYMBOLS

$S$ = distance that rod has dropped, feet

$S_{1}=$ distance that rod has dropped before snubbing begins, feet $S_{2}=f u l 1$ distance of rod travel, feet

$S_{m}=$ distance rod has dropped when torque radius equals $r_{m}$ (see $r_{m}$ below)

$t=$ time since rod was dropped, seconds

$t_{1}=$ time required for rod to fall to the position when snubbing begins, seconds

$t_{2}=$ full insertion time, seconds

$r=$ torque radius of cable as $1 t$ unwinds from the drum, feet

$r_{0}=$ radius of constant diameter portion of drum, feet.

$r_{m}=$ torque radius at which maximum curvature of the cable on the conical portion of the drum occurs, feet

$\mathrm{W}=$ welght of rod, pounds

$I=$ effective moment of inertia of the drum, pound-feet ${ }^{2}$

$\omega=$ angular velocity of $\mathrm{drum}, \operatorname{radians} / \mathrm{sec}$

$E_{\mathrm{R}}=$ kinetic energy of rod, foot-lbs

$\mathrm{E}_{\mathrm{D}}=\mathrm{kinetic}$ energy of drum, foot-ibs

$\mathrm{v}=$ velocity of rod, feet per second

$\mathrm{v}_{1}=$ velocity of rod when snubbing begins, feet per second

$\mathrm{v}_{\mathrm{m}}=\begin{gathered}\text { velocity of rod when torque radius } r_{\mathrm{m}} \text { is reached, feet } \\ \text { per second }\end{gathered}$

$a=$ acceleration of rod in direction of fall, feet per second ${ }^{2}$

$\mathrm{g}=$ acceleration of gravity, $32 \mathrm{feet} / \mathrm{sec}^{2}$

$\mathrm{T}=$ tension in cables, pounds

$F=$ net force acting on the rod, pounds 